\title{
Rancang Bangun dan Unjuk Kerja Generator Mini Magnet Permanen NdFeB Fluks Radial sebagai Lampu Indikator Emergency
}

\author{
Achmad Maulana Soehada S. \\ Program Studi Teknik Mesin, Universitas Pamulang, Jl. Surya Kencana No. 1, Tangerang Selatan, Indonesia \\ E-mail: maulana@gmail.com
}

Masuk:24 Oktober $2017 \quad$ Direvisi : 1 November $2017 \quad$ Disetujui : 14 November 2017

\begin{abstract}
Abstrak: Rancang bangun generator mini tipe fluks radial telah berhasil dibuat dimana rotor didesain dengan menggunakan bahan magnet permanen $\mathrm{NdFeB}$ berbentuk rectangular sebanyak 8 buah (kerapatan fluks magnet 1,28 T). Stator dibuat dengan menggunakan 7 buah kumparan dari kawat tembaga dengan diameter sebesar 0,3 $\mathrm{mm}$ dan jumlah lilitan sebanyak 218. Unjuk kerja generator minifluks radial diukur sebagai fungsi kecepatan putar rotor (540 sampai 660 rpm) terhadap output tegangan, arus listrik, daya listrik dan intensitas cahaya yang dihasilkan. Hasil unjuk kerja generator listrik tanpa beban menunjukkan output tegangan maksimum adalah sebesar 219 volt pada kecepatan putar rotor $660 \mathrm{rpm}$. Pada saat kecepatan putar yang sama dan diberi beban lampu pijar $10 \mathrm{~W}$ diperoleh output tegangan, arus listrik, daya listrik dan intensitas cahaya masing-masing sebesar $185 \mathrm{~V}, 0,36 \mathrm{~A}, 66,6 \mathrm{~W}$ dan $280 \mathrm{Cd}$. Dengan demikian generator minifluks radial ini dapat diaplikasikan sebagai lampu indikator emergensi (tanda bahaya), khususnya di jalan tol (daerah licin).
\end{abstract}

Kata kunci: magnet $\mathrm{NdFeB}$, generator mini, fluks radial, output tegangan, intensitas cahaya

Abstract: A flux radial generator have been constructed and tested where the rotor was designed using 8 NdFeB permanent magnets that have rectangular shape (flux density of 1,28 T each). The stator was designed using 7 coils from copper wire with the diameter of $0,3 \mathrm{~mm}$ and 218 winding each. The performances of this flux radial generator were tested using different rotation variations (540-660 rpm) as a function of output voltage, current, electrical power and light intensity. The tests suggested that the maximum output voltage of $219 \mathrm{~V}$ can be obtained at the rotation of $660 \mathrm{rpm}$. At the same condition with $10 \mathrm{~W}$ load from the lamp, some parameters were achieved: output voltage, current, electrical power and light intensity of $185 \mathrm{~V}$; 0,36A; 66,6 $\mathrm{W}$ and $280 \mathrm{Cd}$, respectively. Thus this mini flux radial generator can be applied as an emergency lamp indicator, particularly on the highway (slippery road).

Keywords: NdFeB magnet, mini generator, flux radial, output voltage, light intensity

\section{PENDAHULUAN}

Masih banyak wilayah Indonesia yang belum teraliri listrik, terutamadaerah terpencil, perbatasan dan pulaupulau terluar [1]. Untuk mengatasi masalah tersebut maka dibutuhkan sumber energi alternatif, seperti energi baru dan terbarukan sebagai penghasil listrik. Salah satu upaya mengatasi kelangkaan energi listrik adalah dengan pemanfaatan energi air dan angin dalam pembangkit energi listrik baik dalam skala besar maupun dalam skala kecil [2]. Indonesia memiliki potensi angin yang cukup besar terkait dengan bidang energi, namun sistem ini juga memerlukan batere atau media penyimpanan energi. Inovasi terhadap teknologi konversi energi terutama pada generator listrik magnet permanen $\mathrm{NdFeB}$ tipe fluks radial dan aksial telah banyak dikembangkan [3-8]. Generator listrik adalah sebuah peralatan yang dapat mengubah energi mekanik (gerak) menjadi energi listrik $[9,10]$.

Prinsip dari pembangkit listrik tenaga angin tipe Savonius adalah mengubah energi kinetik dari sudu-sudu turbin yang berputar akibat kecepatan angin sehingga memutar generator dan menghasilkan listrik [11-14]. Kinerja komponen generator pada tipe pembangkit listrik ini sangat tergantung pada jumlah dan distribusi 
medan magnetik dari magnet permanen $\mathrm{NdFeB}$ yang digunakan [2,3]. Selain itu pengaruh parameter desain, kecepatan putar juga mempengaruhi unjuk kerja generator tersebut [15-16].

Pada penelitian ini akan dilakukan rancang bangun generator listrik magnet permanen NdFeB fluks radial model sederhana untuk emergency lamp. Variabel penelitian adalah kecepatan putar rotor sebagai fungsi dari output tegangan tanpa dan dengan beban lampu pijar $10 \mathrm{~W}$, arus listrik, daya listrik dan intensitas cahaya. Sedangkan besaran lainnya, seperti: jumlah kumparan, jumlah magnet, jumlah sudu turbin dan besaran lainnya adalah tetap. Berdasarkan daya luaran dari generator listrik magnet permanenNdFeB tipe fluks radial sangat dimungkinkan dapat diaplikasikan sebagai sumber energi listrik pada lampu darurat (emergency lamp) di jalan tol khususnya daerah tikungan dan licin.

\section{METODOLOGI}

Disain dan konstruksi generator fluks radial manet permanen $\mathrm{NdFeB}$ satu fasa yang dibuat terdiri dari stator dan rotor. Stator terdiri dari kumparan kawat tembaga (koil) dengan diameter kawat tembaga $3 \mathrm{~mm}$, digulung hingga mencapai jumlah 218 lilitan dan dibentuk seperti terlihat pada Gambar 1a. Panjang bagian luar, $\mathrm{P}_{\mathrm{O}}=120$ $\mathrm{mm}$, bagian dalam, $\mathrm{P}_{\mathrm{IN}}=85 \mathrm{~mm}$, lebar bagian luar, $\mathrm{I}_{\mathrm{O}}=50 \mathrm{~mm}$, bagian dalam, $\mathrm{I}_{\mathrm{IN}}=20 \mathrm{~mm}$ dan tebal kumparan, $\mathrm{T}_{\mathrm{K}}=10 \mathrm{~mm}$. Kumparan koil ini dibuat satu fasa, $\mathrm{N}_{\mathrm{PH}}=1$ dan mempunyai hambatan total $=97,7 \Omega$.

Rotor dibuat berbentuk cincin selinder, diameter $200 \mathrm{~mm}$, tinggi $130 \mathrm{~mm}$ dan tebal $2 \mathrm{~mm}$, berfungsi sebagai tempat dudukan magnet permanen NdFeB sebanyak 8 buah. Magnet NdFeB yang digunakan berbentuk kotak dengan dimensi, panjang, $\mathrm{P}=150 \mathrm{~mm}$, lebar, $\mathrm{L}=50 \mathrm{~mm}$ dan tebal, $\mathrm{T}=10 \mathrm{~mm}$. Susunan magnet diperlihatkan seperti terlihat pada Gambar 1b, dengan jarak antara magnet adalah $20 \mathrm{~mm}$. Sedangkan model generator fluks radial diperlihatkan seperi pada gambar 1c. Jarak celah udara (air gap) antara statordan rotor dibuat tetap sebesar $5 \mathrm{~mm}$, dan poros turbin dipasang tegak lurus pada posisi tengah dengan diameter poros adalah $20 \mathrm{~mm}$.

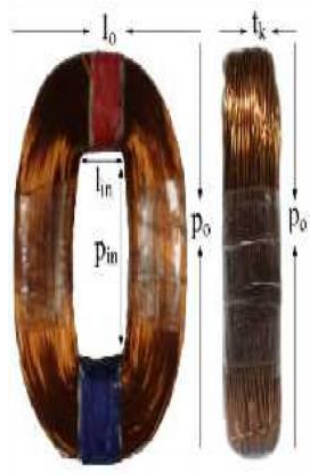

a)

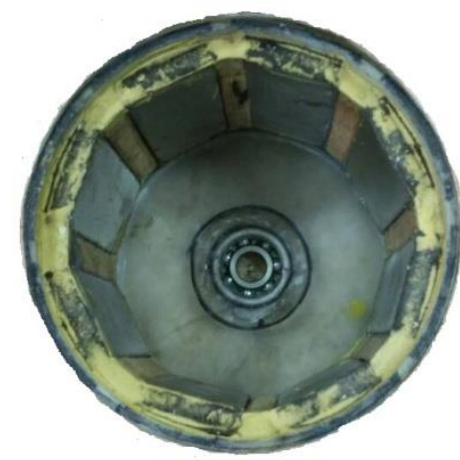

b)

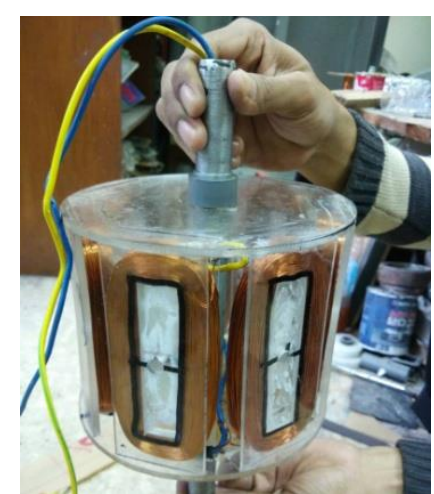

c)

Gambar 1. a). Bentuk dan dimensi kumparan stator, b). Susunan magnet permanen NdFeB pada rotor, dan c). Model generator fluks radial.

Pada Gambar 2, ditunjukkan bentuk fisik generator fluks radial yang telah dibuat (a), bentuk sudu turbin yang dipasang pada generator (b) dan (c) potongan atas dan depan generator fluks radial yang sudah siap untuk diujicoba. Jumlah sudu turbin dibuat tetap sebanyak 16 buah yang terbuat dari pipa paralon dengan diameter 100 $\mathrm{mm}$, panjang $500 \mathrm{~mm}$ dan tebal $2 \mathrm{~mm}$.

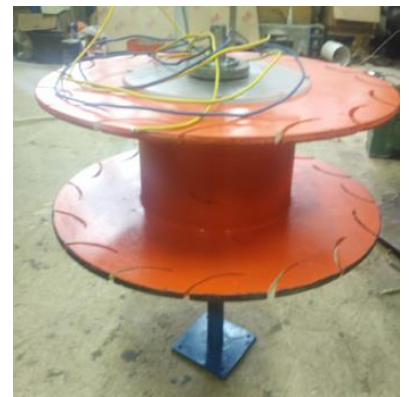

a)

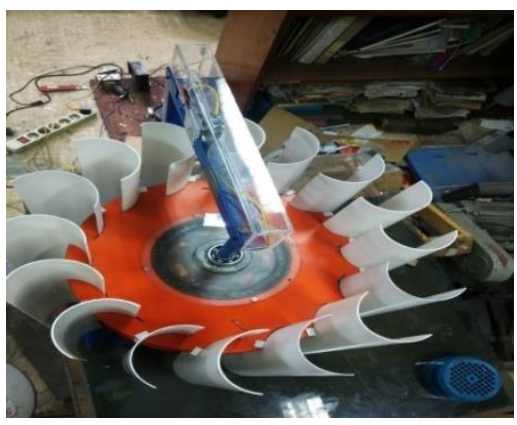

b)

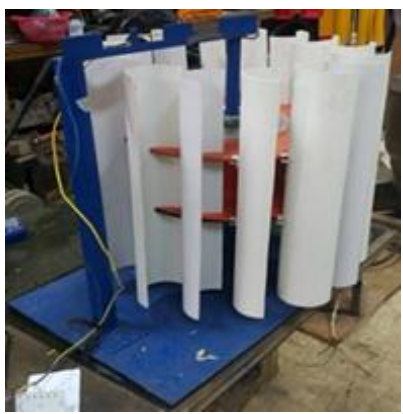

c)

Gambar 2. a). Bentuk generator fluks radial, b). Tampak atas susunan sudu turbin pada generator magnet permanen $\mathrm{NdFeB}$ dan c). Tampak depan generator fluks radial. 
Pengujian unjuk kerja generator magnet permanen NdFeB fluks radial dilakukan meliputi kecepatan putar rotor diukur dengan menggunakan tachometer, output tegangan dan arus diukur dengan multimeter dan intensitas cahaya diukur dengan Lux meter dalam satuan candela (Cd). Candela adalah satuan cahaya yang dianggap sama dengan cahaya lilin yang mempunyai sifat menyebar dan dihitung dari kekuatan intensitas cahayas eluruhnya. Sedangkan daya listrik dihitung berdasarkan nilai output tegangan dan arus yang dihasilkan dengan menggunakan beban lampu pijar 10 watt.

\section{HASIL DAN PEMBAHASAN}

Pada Gambar 3, diperlihatkan hubungan antara kecepatan putar rotor terhadap output tegangan baik tanpa maupun dengan beban lampu pijar 10 watt. Dari gambar 1 , terlihat bahwa output tegangan tanpa beban $\left(\mathrm{V}_{\mathrm{TB}}\right)$ relatif lebih tinggi dibanding output tegangan dengan beban $\left(\mathrm{V}_{\mathrm{DB}}\right)$ pada kecepatan rotor (X) yang sama. Perbedaan ini diakibatkan torsi yang dihasilkan dengan beban lampu pijar 10 watt lebih besar dibanding tanpa beban. Output tegangan tanpa beban $\left(\mathrm{V}_{\mathrm{TB}}\right)$ memenuhi persamaan $\mathrm{V}_{\mathrm{TB}}=0,562 \mathrm{X}-157,2$ dengan tingkat ketelitian mencapai 96,6\%. Sedangkan output tegangan dengan beban, $\mathrm{V}_{\mathrm{DB}}=0,362 \mathrm{X}-56,25$ dan ketelitian mencapai $98,3 \%$. Persamaan di atas hanya berlaku dengan syarat batas kecepatan rotor, X antara 540 sampai $660 \mathrm{rpm}$.

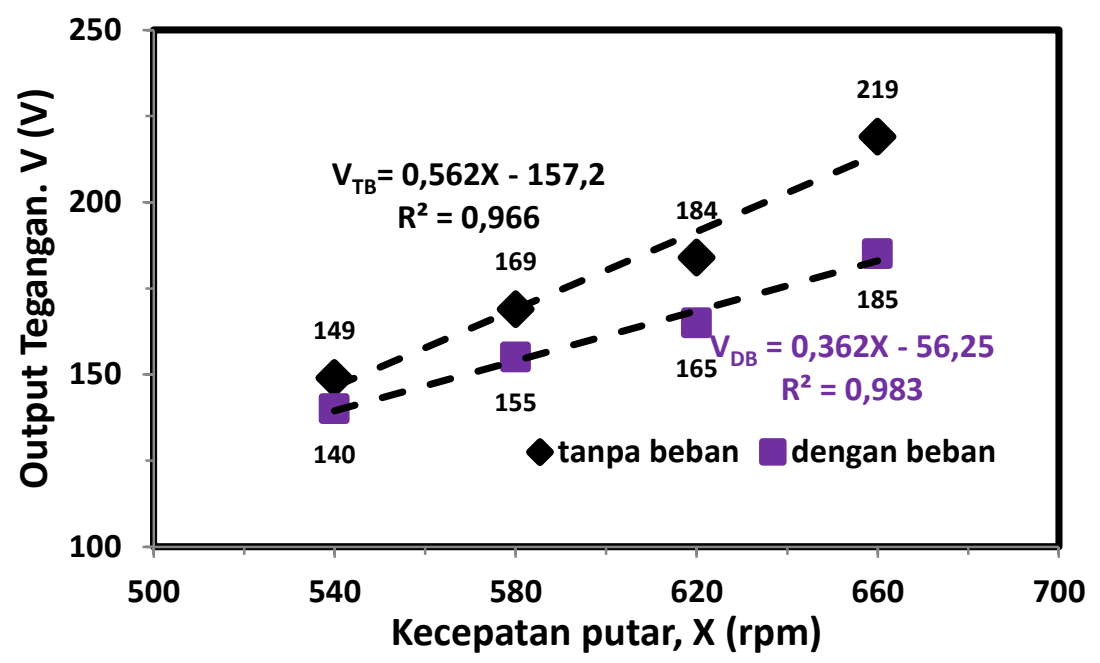

Gambar 3. Hubungan antara kecepatan putar rotor terhadap output tegangan tanpa dan dengan beban lampu pijar $10 \mathrm{~W}$.

Pada Gambar 4, menunjukkan bentuk gelombang sinusoida dari generator fluks radial satu fasa dengan a). tanpa beban dan b). beban lampu pijar $10 \mathrm{~W}$. Dari gambar sumbu Y berkorelasi dengan amplitudo atau output tegangan dan sumbu $\mathrm{X}$ berkorelasi dengan priode, waktu, panjang gelombang dan atau frekuensi. Gelombang sinusoida ini merupakan hasil dari gerakan rotasi yang dihasilkan oleh rotor dan berputar secara periodik.

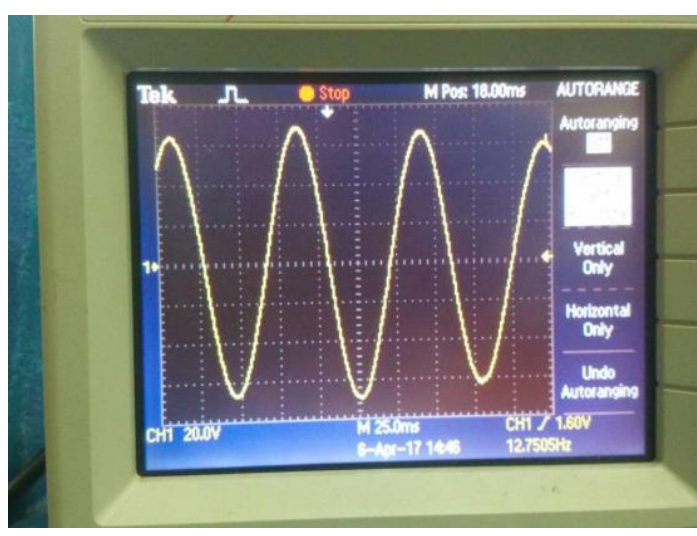

a)

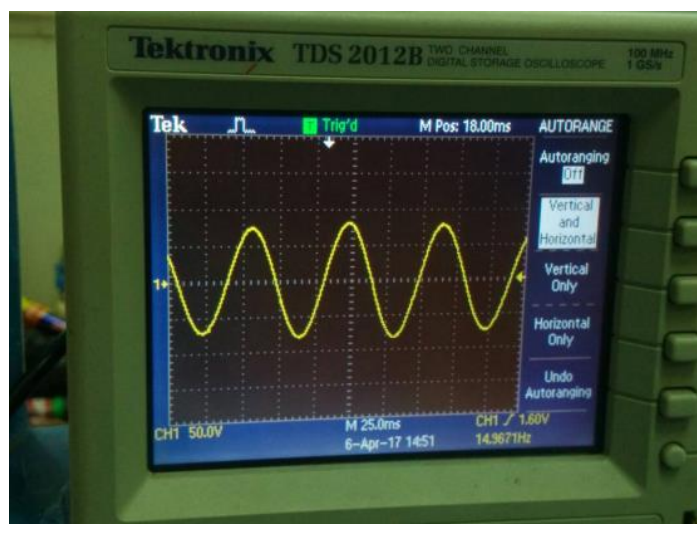

b)

Gambar 4. a).Bentuk sinusoidal dari output tegngan tanpa beban dan b).Bentuk sinusoidal dari output tegangan dengan beban lampu pijar $10 \mathrm{~W}$. 
Pada Gambar 5, diperlihatkan hubungan antara kecepatan putar rotor (X) terhadap output tegangan (V) dan arus listrik (I) dengan beban lampu pijar $10 \mathrm{~W}$. Korelasi output tegangan, V terhadap arus listrik, I adalah berbanding lurus, artinya semakin besar tegangan yang dihasilkan maka arus listrik juga akan semakin besar. Dari hubungan antara V dan I ini menunjukkan adanya besaran yang tetap (konstan) merupakan nilai dari resistansi, R dalam satuan ohm. Akan tetapi nilai resistansi, R akan turun dengan naiknya kecepatan putar rotor atau bertambahnya output tegangan generator tersebut. Nilai arus listrik, $\mathrm{I}=0,001 \mathrm{X}-0,54$, merupakan persamaan garis dan $\mathrm{X}$ adalah kecepatan putar rotor dan tingkat ketelitiannya adalah sebesar 97,2\%. Formula ini hanya berlaku dengan syarat batas nilai X antara 540 sampai $660 \mathrm{rpm}$.

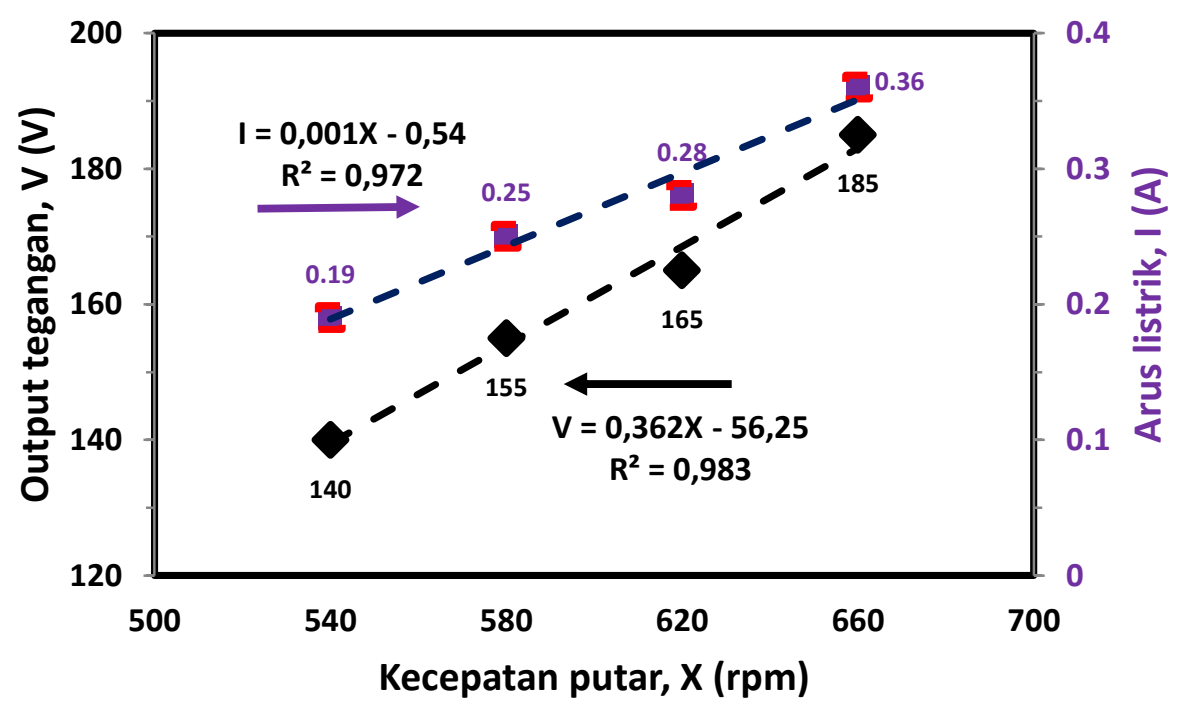

Gambar 5. Hubungan antara kecepatan putar rotor (X) terhadap output tegangan (V) dan arus listrik (I) dengan beban lampu pijar $10 \mathrm{~W}$.

Pada Gambar 6, diperlihatkanhubungan antara kecepatan putar rotor $(\mathrm{X})$ terhadap daya listrik $(\mathrm{P})$ dan intensitas cahaya (L) dengan beban lampu pijar $10 \mathrm{~W}$. Hubungan antara daya listrik, P (W) dan intensitas cahaya, $\mathrm{L}$ (candela $=\mathrm{Cd}$ ) masing-masing terhadap kecepatan putar rotor $(\mathrm{X})$ memenuhi persamaan garis, yaitu: $\mathrm{P}=0,323 \mathrm{X}-149$ dan $\mathrm{L}=1,367 \mathrm{X}-610,7$. Tingkat ketelitian pengukuran daya listrik, $\mathrm{P}$ mencapai $98 \%$ dan intensitas cahaya, L sebesar 96,1\%. Dengan demikian dapat dikatakan bahwa daya listrik semakin besar tentu intensitas cahaya dari lampu tersebut akan semakin terang.

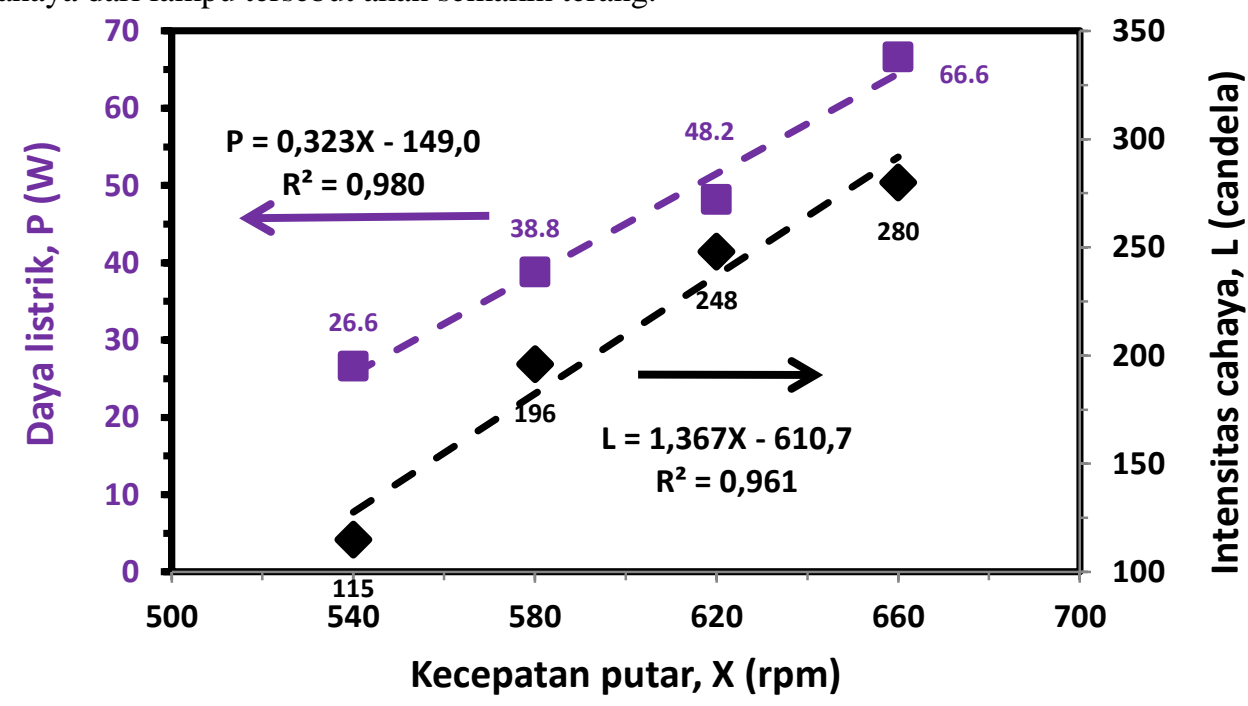

Gambar 6. Hubungan antara kecepatan putar rotor $(\mathrm{X})$ terhadap daya listrik $(\mathrm{P})$ dan intensitas cahaya $(\mathrm{L})$ dengan beban lampu pijar $10 \mathrm{~W}$. 


\section{KESIMPULAN}

Telah berhasil dibuat rancang bangun generator minifluks radial magnet permanenNdFeB sederhana.Dari hasil rancang bangun generator minifluks radialmagnet permanen ini menunjukkan adanya korelasi linier antara output tegangan, arus listrik, daya listrik dan intensitas cahaya terhadap kecepatan putar rotor. Pada saat generator listrik bekerja tanpa beban dan kecepatan putar rotor maksimum sebesar $660 \mathrm{rpm}$ diperoleh output tegangan $219 \mathrm{~V}$. Sedangkan pada saat diberi beban lampu pijar $10 \mathrm{~W}$ dihasilkan output tegangan, arus listrik, daya listrik dan intensitas cahaya masing-masing sebesar $185 \mathrm{~V}, 0,36 \mathrm{~A}, 66,6 \mathrm{~W}$ dan $280 \mathrm{Cd}$. Dengan demikian generator minifluks radial ini lebih tepat diaplikasikan sebagai lampu emergensi (tanda bahaya), khususnya di jalan tol daerah tikungan dan licin.

\section{DAFTAR PUSTAKA}

[1] Daryanto Y 2007 Kajian Potensi Angin Untuk Pembangkit Listrik Tenaga Bayu (Balai PPTAGG-UPT-LAGG)

[2] Gieras J F, Wang R J dan Kamper M J 2008 Axial Flux Permanent Magnet Brushless Machines, 2nd ed. (Springer)

[3] Muljadi, Sardjono P dan Suprapedi 2015 Energy Procedia 68282

[4] Soehada A M, Sebayang P dan Kurniawan C 2017 Piston 16

[5] Nurdiyansyah L F, Tetuko A P, Aryanto D dan Sebayang P 2016 Telaah 329

[6] Simbolon S, Tetuko A P, Sebayang K dan Sebayang P 2017 Piston 11

[7] Tetuko A P, Kurniawan C dan Sebayang P 2013 Simulasi Flux Density Permanent Magnet NdFeB untuk Aplikasi Generator Listrik Prosiding Seminar Nasional Kimia Terapan Indonesia, Solo, 23 Mei 2013, 685

[8] Yanti Y, Nurdiyansah L F, Tetuko A P, Siregar M R T dan Sebayang P 2013 Rancang Bangun Generator Mini Tipe Aksial Dengan Menggunakan Magnet Permanen NdFeB dan Kajiannya, Seminar dan Focus Group Discussion (FGD) Material Maju: Magnet dan Aplikasinya.

[9] Davila-Vilchis J M dan Mishr R S 2014 Energy 65631

[10] Gargov N P, Zobaa A F dan Pisica I 2014 Electric Power Systems Research 10963

[11] AhSahaUK dan RajkumarMJ Renewable Energy 311776

[12] Loganathan B, Mustary I, Chowdhury H dan Alam F 2017 Energy Procedia 110555

[13] Ahmed D and Ahmad A 2013 Journal of Physics: Conference Series 439012039

[14] Eriksson S dan Bernhoff H 2011 Applied Energy 88265

[15] Feiand W dan Luk P C K 2009 Design and performance analysis of a high-speed air-cored axial-flux permanentmagnet generator with circular magnets and coils Proc. IEEE int. Eletric Machines \& Drives conf. p.1

[16] Kurt E, Gör H dan Demirtas M 2014 Energy Conversionand Management 77163 